\title{
Unplanned conversion during minimally invasive liver resection for hepatocellular carcinoma: risk factors and surgical outcomes
}

\author{
Jee Yeon Lee, Seoung Yoon Rho, Dai Hoon Han, Jin Sub Choi, Gi Hong Choi \\ Division of Hepatobiliary and Pancreas Surgery, Department of Surgery, Yonsei University College of Medicine, Seoul, Korea
}

\begin{abstract}
Purpose: Unplanned conversion is sometimes necessary during minimally invasive liver resection (MILR) of hepatocellular carcinoma ( $\mathrm{HCC}$ ). The aims of this study were to compare surgical outcomes of planned MILR and unplanned conversion and to investigate the risk factors after unplanned conversion.

Methods: We retrospectively analyzed 286 patients who underwent MILR with HCC from January 2006 to December 2017. All patients were divided into a MILR group and an unplanned conversion group. The clinicopathologic characteristics and outcomes were compared between the 2 groups. In addition, surgical outcomes in the conversion group were compared with the planned open surgery group $(n=505)$. Risk factors for unplanned conversion were analyzed.

Results: Of the 286 patients who underwent MILR, 18 patients (6.7\%) had unplanned conversion during surgery. The unplanned conversion group showed statistically more blood loss, higher transfusion rate and postoperative complication rate, and longer hospital stay compared to the MILR group, whereas no such difference was observed in comparison with the planned open surgery group. There were no significant differences in overall and disease-free survival among 3 groups. The right-sided sectionectomy (right anterior and posterior sectionectomy), central bisectionectomy and tumor size were risk factors of unplanned conversion.

Conclusion: Unplanned conversion during MILR for HCC was associated with poor perioperative outcomes, but it did not affect long-term oncologic outcomes in our study. In addition, when planning right-sided sectionectomy or central bisectionectomy for a large tumor (more than $5 \mathrm{~cm}$ ), we should recommend open surgery or MILR with an informed consent for unplanned open conversions.

[Ann Surg Treat Res 2020;98(1):23-30]
\end{abstract}

Key Words: Hepatocelluar carcinoma, Minimally invasive liver resection, Open conversion

\section{INTRODUCTION}

Since the introduction of laparoscopic liver resection in the early 1990s, current laparoscopic liver resection is considered as an oncologically safe and standard procedure owing to the development of technical advances and postoperative management [1,2]. Previous studies on surgical outcomes between laparoscopic and open liver resection showed that laparoscopic liver resection provided improved perioperative outcomes and comparable long-term oncologic outcomes [1-3].

Although laparoscopic liver resection has increased in recent years, it is still difficult for many surgeons to perform because of the inherent limitation of laparoscopic techniques such as the fulcrum effect and the restricted degrees of motions of the instrument [4]. Regardless of technical limitations, the 3-dimensional complex anatomy of the liver, with its
Received August 28, 2019, Revised October 18, 2019,

Accepted November 13, 2019

\section{Corresponding Author: Gi Hong Choi}

Department of Surgery, Yonsei University College of Medicine, 50-1

Yonsei-ro, Seodaemun-gu, Seoul 03722, Korea

Tel: +82-2-2228-2099, Fax: +82-2-312-8289

E-mail: choigh@yuhs.ac

ORCID: https://orcid.org/0000-0002-1593-3773
Copyright (c) 2020, the Korean Surgical Society

(c) Annals of Surgical Treatment and Research is an Open Access Journal. All articles are distributed under the terms of the Creative Commons Attribution NonCommercial License (http://creativecommons.org/licenses/by-nc/4.0/) which permits unrestricted non-commercial use, distribution, and reproduction in any medium, provided the original work is properly cited. 
accompanying high risk for significant bleeding, has made laparoscopic liver resection the last area of laparoscopy to be developed [5]. According to the Morioka consensus conference in 2014, laparoscopic major liver resection was considered to be an innovative procedure, even though they agreed that laparoscopic minor liver resection had become a standard procedure [5]. The main concern of minimally invasive liver resection (MILR) is unplanned open conversion, the rate of which varies from $0.0 \%$ to $55.0 \%$ depending on the extent of liver resection and according to the literature [6-10]. According to recent studies comparing planned surgery and unplanned conversion during MILR, this unplanned conversion is known to have a negative effect on perioperative outcomes $[2,7-9,11]$. However, there are few studies about the effect of unplanned conversion on long-term outcomes in patients with hepatocellular carcinoma (HCC) [2].

The aims of this study were to compare the short- and longterm outcomes of MILR and unplanned conversion and to investigate the risk factors after unplanned conversion.

\section{METHODS}

Data from all consecutive patients who underwent MILR from January 2006 to December 2017 at Severance Hospital, Yonsei University College of Medicine, were retrospectively collected from electronic medical records. Patients who underwent open hepatectomy during the same period were also included for analysis. This study was approved by the Severance Hospital's Institutional Review Board (IRB No. 4-20190603) that waived the requirement of informed consent.

The initial selection criterion for laparoscopic liver resection was strictly based on the Louisville Statement [12]: a solitary lesion, tumor size of $5 \mathrm{~cm}$ or less, and located in peripheral liver segments 2 to 6 [13]. Robotic liver resection program in our institute was started in 2008 [4]. Unlike laparoscopic liver resection, initial indications of robotic liver resection were mainly major liver resection [4,14]. As surgeon's experience accumulated, laparoscopic liver resection has been extended into major liver resection and right-sided anatomic liver resection $[1,13]$. Currently, tumor size and number are no longer limiting factors for MILR, while curative removal of HCC is anticipated.

\section{Comparison of short- and long-term outcomes between planned surgery and unplanned conversion groups}

Short-term outcomes were evaluated using operative time, blood loss, transfusion rate, complications, and length of hospital stay. Postoperative complications were assessed according to the Clavien-Dindo classification. R0 status and resection margin were also compared to assess short-term oncologic outcomes. To assess long-term surgical outcomes, disease-free and overall survivals were analyzed. Disease-free survival was defined as the duration from the date of surgery to the day of HCC recurrence diagnosis. Overall survival was defined as the duration from the date of operation to the last follow-up day or death date from any cause.

\section{Risk factors for unplanned open conversion}

Risk factors associated with unplanned open conversion were investigated using age, sex, body mass index (BMI), tumor size, American Joint Committee on Cancer (AJCC) 8th $\mathrm{T}$ stage, presence of liver cirrhosis, platelet count, and extent of resection. Extent of resection was classified into minor liver resection, right-sided sectionectomy and central bisectionectomy, and major hemihepatectomies. Minor hepatic resection included wedge resection, segmentectomy, and left lateral sectionectomy. Right-sided sectionectomy included right anterior sectionectomy and right posterior sectionectomy. Right and left hemihepatectomy were defined as major hemihepatectomies.

\section{Statistical analysis}

Clinicopathologic findings and long-term oncologic outcomes of this study were analyzed using the IBM SPSS Statistics ver. 25.0 (IBM Co., Armonk, NY, USA). For each clinicopathologic finding, each categorical and continuous variable were analyzed with the chi-square and Student t-test. Overall and disease-free survival were analyzed using the Kaplan-Meier method, and the difference in survival curves between groups was expressed using the log-rank test. All P-values < 0.05 (2-sided) were considered statistically significant. A logistic regression model was used to examine the risk factor of unplanned conversion, which was assessed by the Hosmer-Lemeshow goodness-of-fit test.

\section{RESULTS}

\section{Comparison of clinicopathologic characteristics and reasons for unplanned conversion}

Patient- and tumor-specific variables of each group are described in Table 1. Of the 286 patients who underwent MILR, 18 patients $(6.7 \%)$ proceeded to unplanned conversion during surgery. There were no significant differences in liver function, tumor marker, and demographic characteristics such as age, sex, BMI, and comorbid status of each patient. When comparing the operation type between the groups, right-sided sectionectomy and central bisectionectomy have relatively higher unplanned conversion rate. In the pathologic finding, there were no significant differences in the presence of liver cirrhosis and tumor number, T stage according to AJCC 8th classification, microvascular invasion, satellite nodule, $\mathrm{R}$ status, and resection 
Table 1. Comparison of clinicopathologic characteristics and operation type for hepatocellular carcinoma patients

\begin{tabular}{|c|c|c|c|c|c|c|}
\hline Variable & $\operatorname{MILR}(\mathrm{n}=268)$ & $\begin{array}{l}\text { Unplanned } \\
\text { conversion } \\
\quad(n=18)\end{array}$ & P-value & $\begin{array}{l}\text { Unplanned } \\
\text { conversion } \\
\quad(n=18)\end{array}$ & $\begin{array}{l}\text { Planned open } \\
\quad(n=505)\end{array}$ & P-value \\
\hline Age (yr) & $57.7 \pm 9.8$ & $60.2 \pm 11.6$ & 0.438 & $60.2 \pm 11.6$ & $58.0 \pm 9.7$ & 0.384 \\
\hline Sex & & & 0.766 & & & 0.817 \\
\hline Male & $200(74.6)$ & $14(77.8)$ & & $14(77.8)$ & $404(80.0)$ & \\
\hline Female & $68(25.4)$ & $4(22.2)$ & & $4(22.2)$ & $101(20.0)$ & \\
\hline Body mass index $\left(\mathrm{kg} / \mathrm{m}^{2}\right)$ & $23.5 \pm 2.8$ & $24.0 \pm 3.4$ & 0.476 & $24.0 \pm 3.4$ & $24.0 \pm 3.2$ & 0.950 \\
\hline Hypertension & $84(31.3)$ & 7 (38.9) & 0.506 & 7 (38.9) & $128(25.3)$ & 0.197 \\
\hline Diabetes mellitus & $50(18.7)$ & $4(22.2)$ & 0.708 & $4(22.2)$ & $76(15.0)$ & 0.406 \\
\hline Etiology & & & 0.343 & & & 0.491 \\
\hline HBV & $226(84.3)$ & $14(77.8)$ & & $14(77.8)$ & $411(81.4)$ & \\
\hline $\mathrm{HCV}$ & $14(5.2)$ & $0(0)$ & & $0(0)$ & $28(5.5)$ & \\
\hline Alcoholism & $5(1.9)$ & $1(5.6)$ & & $1(5.6)$ & $11(2.2)$ & \\
\hline NBNC & $23(8.6)$ & $3(16.7)$ & & $3(16.7)$ & $55(10.9)$ & \\
\hline Platelet count $\left(10^{3} / \mu \mathrm{L}\right)$ & $167.1 \pm 56.9$ & $170.3 \pm 54.8$ & 0.817 & $170.3 \pm 54.8$ & $168.3 \pm 68.0$ & 0.903 \\
\hline Serum creatinine $(\mathrm{mg} / \mathrm{dL})$ & $0.85 \pm 0.16$ & $0.86 \pm 0.19$ & 0.788 & $0.86 \pm 0.19$ & $0.87 \pm 0.20$ & 0.832 \\
\hline Serum albumin (g/dL) & $4.3 \pm 0.4$ & $4.2 \pm 0.4$ & 0.088 & $4.2 \pm 0.4$ & $4.3 \pm 1.6$ & 0.662 \\
\hline AST (IU/L) & $41.1 \pm 36.8$ & $45.3 \pm 30.9$ & 0.639 & $45.3 \pm 30.9$ & $35.7 \pm 24.9$ & 0.114 \\
\hline ALT (IU/L) & $38.8 \pm 38.1$ & $36.9 \pm 24.0$ & 0.833 & $36.9 \pm 24.0$ & $35.0 \pm 25.7$ & 0.767 \\
\hline Total bilirubin (mg/dL) & $0.82 \pm 0.36$ & $0.78 \pm 0.40$ & 0.733 & $0.78 \pm 0.40$ & $0.78 \pm 0.36$ & 0.948 \\
\hline INR & $1.08 \pm 0.84$ & $1.01 \pm 0.10$ & 0.736 & $1.01 \pm 0.10$ & $1.00 \pm 0.85$ & 0.422 \\
\hline$\alpha-\mathrm{FP}(\mathrm{ng} / \mathrm{mL})$ & $439.0 \pm 2,615.0$ & $133.5 \pm 305.0$ & 0.621 & $133.5 \pm 305.0$ & $1,048.2 \pm 336.1$ & 0.608 \\
\hline PIVKA-II (mAU/mL) & $481.4 \pm 4,677.0$ & $234.7 \pm 401.3$ & 0.823 & $234.7 \pm 401.3$ & $1,071.7 \pm 5,145.0$ & 0.491 \\
\hline \multicolumn{7}{|l|}{ Pathology } \\
\hline Liver cirrhosis & $135(50.4)$ & $8(44.4)$ & 0.626 & $8(44.4)$ & $298(59.0)$ & 0.218 \\
\hline Tumor number & & & 0.279 & & & 0.638 \\
\hline Single & $244(91.0)$ & $15(83.3)$ & & $15(83.3)$ & $440(87.1)$ & \\
\hline Multiple & $24(9.0)$ & $3(16.7)$ & & $3(16.7)$ & 65 (12.9) & \\
\hline Tumor size $(\mathrm{cm})$ & $2.6 \pm 1.2$ & $3.5 \pm 1.4$ & 0.002 & $3.5 \pm 1.4$ & $3.7 \pm 2.2$ & 0.729 \\
\hline AJCC 8th T stage & & & 0.774 & & & $<0.001$ \\
\hline T1 & $167(62.3)$ & $10(55.6)$ & & $10(55.6)$ & $438(86.7)$ & \\
\hline $\mathrm{T} 2$ & 99 (36.9) & $8(44.4)$ & & $8(44.4)$ & $52(10.3)$ & \\
\hline T3 & $2(0.7)$ & $0(0)$ & & $0(0)$ & $15(3.0)$ & \\
\hline $\mathrm{T} 4$ & $0(0.0)$ & $0(0)$ & & $0(0)$ & $0(0.0)$ & \\
\hline Microvascular invasion & $116(43.9)$ & $7(38.9)$ & 0.676 & $7(38.9)$ & $245(48.5)$ & 0.422 \\
\hline Satellite nodule & $6(2.2)$ & $1(5.6)$ & 0.378 & $1(5.6)$ & $28(5.5)$ & 0.982 \\
\hline Minimally invasive approach & & & 0.435 & & & $<0.001$ \\
\hline Laparoscopy & $227(84.7)$ & $14(77.8)$ & & $14(77.8)$ & $0(0.0)$ & \\
\hline Robot & $41(15.3)$ & $4(22.2)$ & & $4(22.2)$ & $0(0.0)$ & \\
\hline Operation type & & & $<0.001$ & & & $<0.001$ \\
\hline Wedge resection & $100(37.3)$ & $5(27.8)$ & & $5(27.8)$ & $66(13.1)$ & \\
\hline Segmentectomy & $44(16.4)$ & $2(11.1)$ & & $2(11.1)$ & $107(21.2)$ & \\
\hline Left lateral sectionectomy & $41(15.3)$ & $0(0)$ & & $0(0)$ & $26(5.1)$ & \\
\hline Right-sided sectionectomy & $29(10.8)$ & $9(50.0)$ & & $9(50.0)$ & $61(12.1)$ & \\
\hline Central bisectionectomy & $3(1.1)$ & $1(5.6)$ & & $1(5.6)$ & $38(7.5)$ & \\
\hline Left hemihepatectomy & $30(11.2)$ & $0(0)$ & & $0(0)$ & $56(11.1)$ & \\
\hline Right hemihepatectomy & $24(9.0)$ & $1(5.6)$ & & $1(5.6)$ & $10(2.0)$ & \\
\hline
\end{tabular}

Values are presented as mean \pm standard deviation or number of patients $(\%)$.

Right-sided sectionectomy included right anterior sectionectomy and posterior sectionectomy.

MILR, minimally invasive liver resection; NBNC, non-B non-C hepatitis; INR, international normalized ratio; PIVKA-II, protein induced by vitamin K absence or antagonist II; AJCC, American Joint Committee on Cancer. 
margin, but tumor size was found to be larger in the unplanned conversion group than in the MILR group. In the planned open surgery group, the mean tumor size was similar to that of the unplanned conversion group.

The reasons for unplanned conversion are described in Table 2. Bleeding was the most common cause, followed by lack of progression and poor access. Among 18 cases, oncologic concern, diaphragm injury, and severe adhesion were found. Vital signs during conversion were reviewed in the unplanned conversion group. When unstable vital signs were defined as both systolic blood pressure $<90 \mathrm{mmHg}$ and heart rate $>120$ beats/min, none showed unstable vital sign because bleeding was temporarily controlled using hemostatic agents before conversion.

\section{Comparison of perioperative outcomes}

Table 3 shows a comparison of perioperative outcomes

Table 2. Reasons for conversion from MILR to open laparotomy

\begin{tabular}{lc}
\hline \multicolumn{1}{c}{ Reasons for conversion } & $\begin{array}{c}\text { No. of } \\
\text { patients }(\%)\end{array}$ \\
\hline Bleeding & $11(61.1)$ \\
Lack of progression & $2(11.1)$ \\
Poor access & $2(11.1)$ \\
Oncologic concern & $1(5.6)$ \\
Diaphragm injury & $1(5.6)$ \\
Severe adhesion & $1(5.6)$ \\
Total conversions from MILR to open laparotomy & $18(6.7)$ \\
\hline
\end{tabular}

MILR, minimally invasive liver resection.
Table 4. Detailed postoperative complications

\begin{tabular}{lrll}
\hline \multicolumn{1}{c}{ Complication } & $\begin{array}{c}\text { MILR } \\
(\mathrm{n}=268)\end{array}$ & $\begin{array}{l}\text { Unplanned } \\
\text { Conversion } \\
(\mathrm{n}=18)\end{array}$ & P-value \\
\hline Liver-related complications & $10(3.7)$ & $4(22.2)$ & 0.001 \\
Bile leakage & $2(0.7)$ & $0(0)$ & \\
Ascites & $6(2.2)$ & $4(22.2)$ & \\
Biliary stricture & $2(0.7)$ & $0(0)$ & \\
Surgical-related complications & $21(7.8)$ & $5(27.8)$ & 0.006 \\
Wound complication & $9(3.4)$ & $2(11.1)$ & \\
Intraabdominal fluid & $10(3.7)$ & $1(5.6)$ & \\
collection & & & \\
Ileus & $1(0.4)$ & $2(11.1)$ & \\
Fever (no definite focus, & $1(0.4)$ & $0(0)$ \\
$\quad$ antibiotics use) & & & \\
General complications & $23(8.6)$ & $2(11.1)$ & 0.759 \\
Atelectasis & $9(3.4)$ & $0(0)$ & \\
Pneumonia & $2(0.7)$ & $0(0)$ & \\
Pleural effusion & $1(0.4)$ & $1(5.6)$ & \\
Atrial fibrillation & $2(0.7)$ & $0(0)$ \\
Urinary retention & $4(1.5)$ & $0(0)$ \\
Delirium & $3(1.1)$ & $1(5.6)$ & \\
Stroke & $1(0.4)$ & $0(0)$ \\
Pseudomembranous colitis & $1(0.4)$ & $0(0)$ & \\
\hline & &
\end{tabular}

Values are presented as number of patients (proportion per each group).

In 6 cases, there are more than one complications (first case, ascites and pleural effusion; second case, delirium and pseudomembranous colitis; third case, wound complication and intraabdominal fluid collection; fourth case, ileus and delirium; fifth case, delirium and stroke; sixth case, ascites, wound complication, intraabdominal fluid collection, and pleural effusion).

MILR, minimally invasive liver resection.

Table 3. Comparison of perioperative outcomes for hepatocellular carcinoma patients

\begin{tabular}{|c|c|c|c|c|c|c|}
\hline Variable & MILR (n = 268) & $\begin{array}{l}\text { Unplanned } \\
\text { conversion } \\
\quad(\mathrm{n}=18)\end{array}$ & P-value & $\begin{array}{l}\text { Unplanned } \\
\text { conversion } \\
(\mathrm{n}=18)\end{array}$ & $\begin{array}{l}\text { Planned open } \\
\quad(n=505)\end{array}$ & P-value \\
\hline Estimated blood loss (mL) & $221.8 \pm 409.6$ & $847.8 \pm 547.3$ & $<0.001$ & $847.8 \pm 547.3$ & $532.3 \pm 512.8$ & 0.011 \\
\hline Operative time (min) & $302.5 \pm 152.0$ & $441.2 \pm 251.2$ & $<0.001$ & $441.2 \pm 251.2$ & $267.4 \pm 104.1$ & $<0.001$ \\
\hline Blood transfusion & $9(3.4)$ & $6(33.3)$ & $<0.001$ & $6(33.3)$ & $59(11.7)$ & 0.006 \\
\hline Complication $^{\mathrm{a})}$ & $49(18.3)$ & $7(38.9)$ & 0.048 & $7(38.9)$ & $134(26.5)$ & $<0.001$ \\
\hline Grade I & $13(4.9)$ & $0(0)$ & & $0(0)$ & $36(7.1)$ & \\
\hline Grade II & $29(10.8)$ & $6(33.3)$ & & $6(33.3)$ & $699(13.7)$ & \\
\hline Grade III & $6(2.2)$ & $1(5.6)$ & & $1(5.6)$ & $20(4.0)$ & \\
\hline Grade IV & $1(0.4)$ & $0(0)$ & & $0(0)$ & $7(1.4)$ & \\
\hline Grade V & $0(0)$ & $0(0)$ & & $0(0)$ & $2(0.4)$ & \\
\hline Length of stay (day) & $7.6 \pm 4.5$ & $11.2 \pm 4.9$ & 0.001 & $11.2 \pm 4.9$ & $13.2 \pm 17.9$ & 0.631 \\
\hline R0 status & & & 0.652 & & & 0.296 \\
\hline Ro & $265(98.9)$ & $18(100)$ & & $18(100)$ & $477(94.3)$ & \\
\hline $\mathrm{R} 1$ & $3(1.1)$ & $0(0)$ & & $0(0)$ & $28(5.7)$ & \\
\hline Resection margin $(\mathrm{cm})$ & $1.6 \pm 1.4$ & $1.5 \pm 1.1$ & 0.723 & $1.5 \pm 1.1$ & $1.4 \pm 1.5$ & 0.834 \\
\hline
\end{tabular}

Values are presented as mean \pm standard deviation or number of patients (\%).

MILR, minimally invasive liver resection.

${ }^{\text {a) }}$ Clavien-Dindo classification. 
between each group. First, the unplanned conversion group had significantly more blood loss, longer operative time, and higher transfusion rate than the MILR group and planned open surgery group. The incidence of complication according to the Clavien-Dindo classification was higher in the unplanned conversion group. Each complication is categorized as liverrelated, surgical-related, and general complications and described in Table 4. Liver- and surgical-related complications were significantly higher in the unplanned conversion group. The mean postoperative hospital stay was longer in the unplanned conversion group $(\mathrm{P}=0.001)$ compared to the MILR group, but there was no such difference between the unplanned conversion group and thee planned open surgery group $(\mathrm{P}=$ $0.631)$.

\section{Risk factors associated with unplanned conversion}

Logistic regression analysis was performed with multiple factors that could affect unplanned conversion. Age, sex, BMI, presence of liver cirrhosis, and platelet count had no effects on unplanned conversion (Table 5). Tumor size was found to be a significant risk factor for unplanned conversion. Additionally, extent of resection was also a risk factor for unplanned conversion. With respect to extent of resection, right-sided

Table 5. Risk factors associated with unplanned conversion

\begin{tabular}{|c|c|c|c|}
\hline Variable & P-value & $H R$ & $95 \% \mathrm{Cl}$ \\
\hline Age & 0.121 & 1.043 & $0.989-1.100$ \\
\hline \multicolumn{4}{|l|}{ Sex } \\
\hline Male & Reference & & \\
\hline Female & 0.871 & 1.112 & $0.307-4.029$ \\
\hline Body mass index & 0.780 & 1.029 & $0.840-1.261$ \\
\hline \multicolumn{4}{|l|}{ Liver cirrhosis } \\
\hline No & Reference & & \\
\hline Yes & 0.923 & 0.943 & $0.288-3.086$ \\
\hline Platelet count $\left(10^{3} / \mu \mathrm{L}\right)$ & 0.598 & 0.997 & $0.987-1.007$ \\
\hline Tumor size & 0.008 & 1.769 & $1.163-2.690$ \\
\hline \multicolumn{4}{|l|}{ AJCC 8th T stage } \\
\hline T1 & Reference & & \\
\hline $\mathrm{T} 2$ & 0.752 & 1.198 & $0.390-3.678$ \\
\hline T3 & 0.999 & 0.000 & \\
\hline \multicolumn{4}{|l|}{ Extent of resection } \\
\hline $\begin{array}{l}\text { Minor hepatic } \\
\text { resection }\end{array}$ & Reference & & \\
\hline $\begin{array}{l}\text { Right-sided } \\
\text { sectionectomy and } \\
\text { central bisectio- } \\
\text { nectomy }\end{array}$ & 0.001 & 6.793 & $2.283-20.209$ \\
\hline $\begin{array}{l}\text { Major hepatic } \\
\text { resection }\end{array}$ & 0.179 & 0.202 & $0.020-2.085$ \\
\hline
\end{tabular}

Right-sided sectionectomy included right anterior sectionectomy and posterior sectionectomy.

$\mathrm{HR}$, hazard ratio; $\mathrm{Cl}$, confidence interval; AJCC, American Joint Committee on Cancer. sectionectomy and central bisectionectomy were found to be more associated with unplanned conversion compared to minor and major hepatic resections.

\section{Comparison of long-term oncologic outcomes}

Long-term oncologic outcome was analyzed using overall and disease-free survival. In survival analysis, there were no statistically significant differences in overall $(P=0.722)$ (Fig. 1) and disease-free survival ( $P=0.541$ ) (Fig. 2) among 3 groups. Regarding overall survival, MILR and unplanned conversion showed comparable 1- (95.2\% vs. 94.2\%), 3- (89.9\% vs. 94.4\%), and 5 -year overall survival ( $88.3 \%$ vs. $94.4 \%$; Fig. 1). There were no significant differences in 1- $(86.2 \%$ vs. $77.8 \%), 3-(68.2 \%$ vs. $71.3 \%$ ), and 5-year disease-free survival (57.1\% vs. $42.8 \%$ ) (Fig. 2) between the MILR group and the unplanned conversion group.

\section{DISCUSSION}

There has been a dramatic development in laparoscopic liver resection during the last few decades $[1,5,8,12,15,16]$. Recently introduced robotic systems have accelerated the progress of MILR [4,14]. The main advantages of MILR are that they provide patients with smaller scars, better cosmesis, less pain and analgesic requirements, shorter hospital stay, and early return

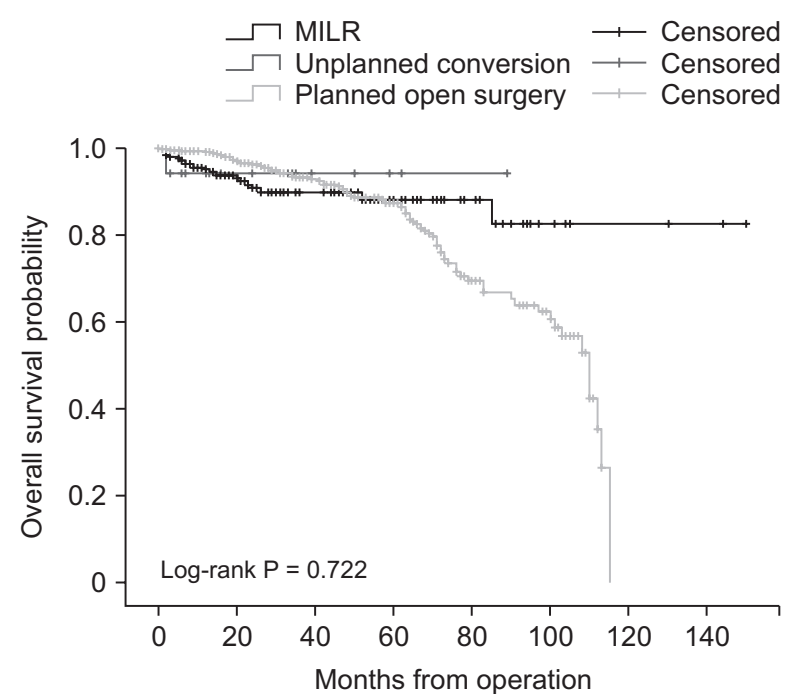

\begin{tabular}{|c|c|c|c|}
\hline OS & $\begin{array}{c}\text { OS } \\
1 \text { year }(\%)\end{array}$ & $\begin{array}{c}\text { OS } \\
3 \text { years (\%) }\end{array}$ & $\begin{array}{c}\text { OS } \\
5 \text { years (\%) }\end{array}$ \\
\hline MILR & 95.2 & 89.9 & 88.3 \\
\hline $\begin{array}{l}\text { Unplanned } \\
\text { conversion }\end{array}$ & 94.4 & 94.4 & 94.4 \\
\hline $\begin{array}{l}\text { Planned open } \\
\text { surgery }\end{array}$ & 99.2 & 93.2 & 87.4 \\
\hline
\end{tabular}

Fig. 1. Comparison of overall survival (OS) among the MILR group, the unplanned conversion group, and the planned open surgery group. MILR, minimally invasive liver resection. 

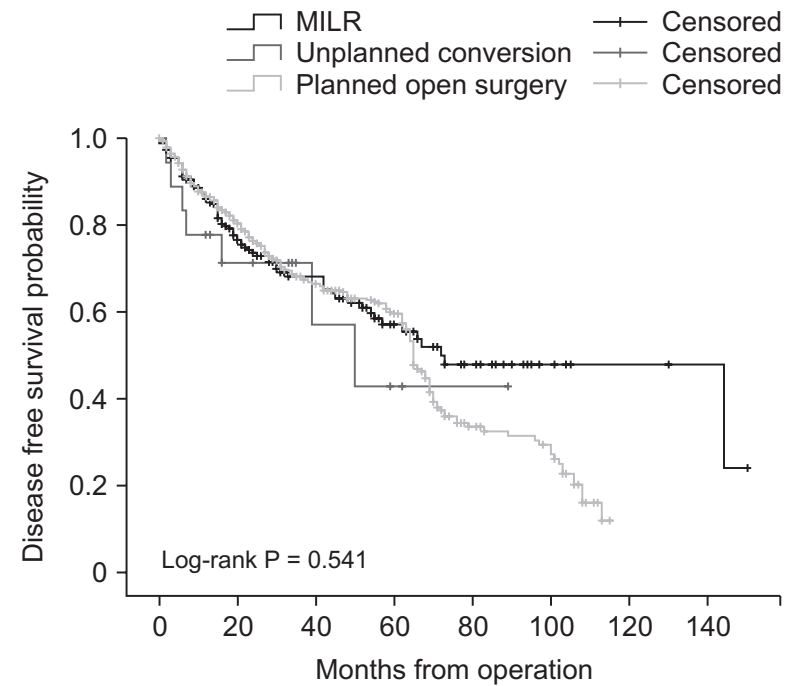

\begin{tabular}{|c|c|c|c|}
\hline DFS & $\begin{array}{c}\text { DFS } \\
1 \text { year }(\%) \\
\end{array}$ & $\begin{array}{c}\text { DFS } \\
3 \text { years }(\%) \\
\end{array}$ & $\begin{array}{c}\text { DFS } \\
5 \text { years }(\%) \\
\end{array}$ \\
\hline MILR & 86.2 & 68.2 & 57.1 \\
\hline $\begin{array}{l}\text { Unplanned } \\
\text { conversion }\end{array}$ & 77.8 & 71.3 & 42.8 \\
\hline $\begin{array}{l}\text { Planned open } \\
\text { surgery }\end{array}$ & 86.7 & 68.1 & 59.5 \\
\hline
\end{tabular}

Fig. 2. Comparison of disease-free survival (DFS) among the MILR group, the unplanned conversion group, and the planned open surgery group. MILR, minimally invasive liver resection.

to social activity without compromising short- and long-term oncologic outcomes $[1,5,8,12]$. From the Louisville Statement to the Morioka consensus conference, laparoscopic liver resection has been rapidly popularized, and minor liver resection is now considered a standard procedure, regardless of the size, number, and location of the tumor [5,12]. However, major liver resections are still regarded as an innovative procedure and allowed only in expert centers [5]. The main concern regarding the broader adoption of MILR is an emergency open conversion caused by major bleeding, which may affect postoperative morbidity, mortality, and long-term outcomes $[9,10,17,18]$.

In our study, unplanned open conversion during MILR for HCC was associated with poor short-term outcomes, with significantly longer operative time; more blood loss, and therefore, more requirements for blood transfusion; higher postoperative complication rates; and longer hospital stays. These results are in agreement with those of previous studies $[1,4,8,11,18]$. In particular, bleeding and perioperative blood transfusion are well known to be risk factors for postoperative morbidity [7-11]. The complication rates of the unplanned conversion group were 2 times higher than those of the planned surgery group (38.9\% vs. $18.3 \%$ ) and grade II complications were more common in the unplanned conversion group; however, severe complications (grade > III) were not statistically different in this study.

Compared to the accumulating evidence of negative effects of unplanned open conversion on short-term outcomes, clinical significance of unplanned open conversion group in long-term aspect has been rarely investigated, especially in patients with HCC. Stiles et al. [2] reported the long-term outcomes after unplanned conversion during laparoscopic liver resection in patients with HCC. They found that the unplanned conversion group showed poor overall survival, and the difference was more predominant in patients who experienced open conversion during laparoscopic major hepatectomy. These results may be related to the recent European multicenter study, which found that emergency conversion for unfavorable intraoperative events such as bleeding and oncologic concern was associated with significantly poor short-term outcomes during laparoscopic liver resection, compared to elective conversion for unfavorable intraoperative findings such as adhesions and poor access [18]. Taken together with these 2 studies, conversion during laparoscopic major liver resection may have been performed under emergency conditions due to uncontrolled major bleeding. However, the unplanned conversion group did not show any difference in diseasefree and overall survival compared to the planned surgery group in our study. This result might be caused by the small number of patients in the unplanned conversion group, but more importantly, the different situations and timing of conversion may have rendered our results different from those of previous studies. Even though the main cause of conversion was bleeding like previous studies, open conversion was not performed urgently with unstable vital signs in our patients. When bleeding occurred during MILR, all attempts were applied to control bleeding temporarily. Considering operative time and difficulty in proceeding with the operation, an early decision was made for an open procedure in our study. Costi et al. [19] also demonstrated that not delaying conversion may reduce blood loss and operative time. Nonemergency conditions and early decision for open conversion may have made similar long-term outcomes between the unplanned conversion and planned surgery groups in our study.

Many studies have been conducted assessing the risk factors of such unplanned conversion. Troisi et al. [7] presented tumor location (posterosuperior segments: I, IVa, VI, and VII) and major hepatectomy as predictors of conversion, and Cauchy et al. [11] considered high BMI and large tumor size $(>10 \mathrm{~cm} ; \mathrm{P}=$ 0.014 ) as risk factors. Of the recent papers, Stiles et al. [6] and Vigano et al. [10] analyzed major hepatectomy with predictor of conversion, and Silva et al. [9] found that those with hypertension and those who underwent right hepatectomy had a higher risk of conversion. Previous studies demonstrated that operative difficulty is the most common risk factor for 
conversion. In this study, tumor size, right-sided sectionectomy and central bisectionectomy were identified as risk factors for unplanned conversion. As the tumor size increases, the more major liver resection is required. Right-sided sectionectomy and central bisectionectomy needs 2 different transection planes and the largest transection area possible, which inevitably increases the risk for bleeding and sometimes poor exposure in the deep area during MILR [5].

In conclusion, unplanned open conversion during MILR for HCC was associated with poor perioperative outcomes, but did not affect long-term oncologic outcomes in our data. It may be related to the early decision for open conversion. Therefore, open conversion should not be regarded as a failure of MILR. Moreover, findings from this study suggest that when planning right-sided sectionectomy (right anterior and posterior sectionectomy) or central bisectionectomy for a large tumor (more than $5 \mathrm{~cm}$ ), we should recommend open surgery or MILR with an informed consent for unplanned open conversions.

\section{CONFLICTS OF INTEREST}

No potential conflict of interest relevant to this article was reported.

\section{ACKNOWLEDGEMENTS}

The authors acknowledge Severance Hospital, Yonsei University College of Medicine for their support to perform this study at the institution.

\section{REFERENCES}

1. Han DH, Choi SH, Park EJ, Kang DR, Choi GH, Choi JS. Surgical outcomes after laparoscopic or robotic liver resection in hepatocellular carcinoma: a propensityscore matched analysis with conventional open liver resection. Int J Med Robot 2016;12:735-42.

2. Stiles ZE, Glazer ES, Deneve JL, Shibata D, Behrman SW, Dickson PV. Long-term implication of unplanned conversion during laparoscopic liver resection for hepatocellular carcinoma. Ann Surg Oncol 2019;26:282-9.

3. Andreou A, Struecker B, Raschzok N, Krenzien F, Haber P, Wabitsch S, et al. Minimal-invasive versus open hepatectomy for hepatocellular carcinoma: comparison of postoperative outcomes and long-term survivals using propensity score matching analysis. Surg Oncol 2018; 27:751-8.

4. Choi GH, Chong JU, Han DH, Choi JS, Lee WJ. Robotic hepatectomy: the Korean experience and perspective. Hepatobiliary Surg Nutr 2017;6:230-8.

5. Wakabayashi G, Cherqui D, Geller DA, Buell JF, Kaneko H, Han HS, et al. Recommendations for laparoscopic liver resection: a report from the second international consensus conference held in
Morioka. Ann Surg 2015:261:619-29.

6. Stiles ZE, Behrman SW, Glazer ES, Deneve JL, Dong L, Wan JY, et al. Predictors and implications of unplanned conversion during minimally invasive hepatectomy: an analysis of the ACS-NSQIP database. HPB (Oxford) 2017;19:957-65.

7. Troisi RI, Montalti R, Van Limmen JG, Cavaniglia D, Reyntjens K, Rogiers X, et al. Risk factors and management of conversions to an open approach in laparoscopic liver resection: analysis of 265 consecutive cases. HPB (Oxford) 2014;16: 75-82.

8. Nguyen KT, Gamblin TC, Geller DA. World review of laparoscopic liver resection-2,804 patients. Ann Surg 2009:250: 831-41.

9. Silva JP, Berger NG, Yin Z, Liu Y, Tsai S, Christians KK, et al. Minimally invasive hepatectomy conversions: an analysis of risk factors and outcomes. HPB (Oxford) 2018;20:132-9.

10. Vigano L, Laurent A, Tayar C, Tomatis M, Ponti A, Cherqui D. The learning curve in laparoscopic liver resection: improved feasibility and reproducibility. Ann Surg 2009:250:772-82.

11. Cauchy F, Fuks D, Nomi T, Schwarz L, Barbier L, Dokmak S, et al. Risk factors and consequences of conversion in laparoscopic major liver resection. Br J Surg 2015;102:785-95.

12. Buell JF, Cherqui D, Geller DA, O'Rourke N, Iannitti D, Dagher I, et al. The international position on laparoscopic liver surgery: The Louisville Statement, 2008. Ann Surg 2009;250:825-30.

13. Choi SH, Choi GH, Han DH, Choi JS. Laparoscopic liver resection using a rubber band retraction technique: usefulness and perioperative outcome in 100 consecutive cases. Surg Endosc 2015;29: 387-97.

14. Choi GH, Choi SH, Kim SH, Hwang HK, Kang CM, Choi JS, et al. Robotic liver resection: technique and results of 30 consecutive procedures. Surg Endosc 2012;26:2247-58.

15. Morise Z, Wakabayashi G. First quarter century of laparoscopic liver resection. World J Gastroenterol 2017:23:3581-8.

16. Gagner M, Rheault M, Dubuc J. Laparoscopic partial hepatectomy for liver tumors. Surg Endosc 1992;6:97-8.

17. Gupta R, Fuks D, Bourdeaux C, Radkani P, Nomi T, Lamer C, et al. Impact of intraoperative blood loss on the short-term outcomes of laparoscopic liver resection. Surg Endosc 2017;31:4451-7. 
18. Halls MC, Cipriani F, Berardi G, Barkhatov L, Lainas P, Alzoubi M, et al. Conversion for unfavorable intraoperative events results in significantly worse outcomes during laparoscopic liver resection: lessons learned from a multicenter review of 2861 cases. Ann Surg 2018;268:1051-7.

19. Costi R, Scatton O, Haddad L, Randone B, Andraus W, Massault PP, et al. Lessons learned from the first 100 laparoscopic liver resections: not delaying conversion may allow reduced blood loss and operative time. J Laparoendosc Adv Surg Tech A 2012;22:425-31. 